\title{
Microstructure investigation of the PVD thin films of TRIP steels
}

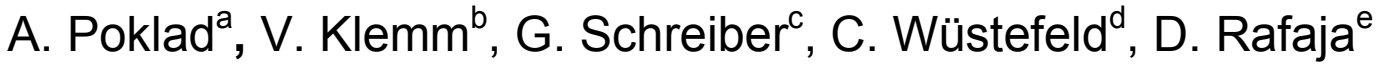 \\ Institute of Materials Science, TU Bergakademie Freiberg, Gustav-Zeuner-Str. 5, \\ D-09599 Freiberg, Germany
}

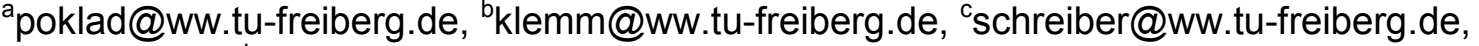 \\ wuestefeld@ww.tu-freiberg.de, ${ }^{\mathrm{d}}$ rafaja@ww.tu-freiberg.de
}

\begin{abstract}
Keywords: thin films, TRIP steel, microstructure, texture, austenite, ferrite.
\end{abstract}
\begin{abstract}
The combination of a TRIP steel with the $\mathrm{MgO}$ stabilized $\mathrm{ZrO}_{2}$ ceramics $(\mathrm{MgO} \cdot \mathrm{ZrO})_{2}$ is regarded as a promising way to increase the energy absorption in engineering materials. An additional contribution to the energy absorption in the counterparts, i.e. in the TRIP steel and in $\mathrm{MgO} \cdot \mathrm{ZrO}_{2}$, is expected to arise at the interfaces between the individual materials. However, the mutual crystallographic orientation of the TRIP steel and $\mathrm{MgO} \cdot \mathrm{ZrO}_{2}$ at their interface plays a crucial role both for the adhesion of the counterparts and for the energy absorption process. In this work, the interfaces between the TRIP steel and $\mathrm{MgO} \cdot \mathrm{ZrO}_{2}$ were studied on simplified systems, which were prepared in form of the TRIP steel thin films that were deposited using the magnetron sputtering on various substrates, e.g. $\mathrm{Si}$ wafer, $\mathrm{MgO} \cdot \mathrm{ZrO}_{2}$ and the $\mathrm{Al}_{2} \mathrm{O}_{3} / \mathrm{ZrO}_{2}$ composites. The substrates were both single-crystalline ( $\mathrm{Si}$ wafer) and polycrystalline $\left(\mathrm{MgO} \cdot \mathrm{ZrO}_{2}, \mathrm{Al}_{2} \mathrm{O}_{3} / \mathrm{ZrO}_{2}\right)$. The basic characteristics of the thin films (morphology, thickness, chemical composition) were obtained from the scanning electron micrographs and from the energy dispersive analysis of the characteristic X-rays (EDX). X-ray diffraction (XRD) and transmission electron microscopy with high-resolution (HRTEM) that was complemented by the Fast Fourier Transform (FFT) of the HRTEM micrographs were employed as the crucial experimental methods for the microstructure analysis of these thin films. XRD was used for the phase analysis and for the global texture analysis. The global texture analysis was performed via the pole figure measurements. FFT/HRTEM was used for the characterisation of the local orientation relationships between the TRIP steel and the respective substrate and for the visualisation of the interfaces between individual crystallites.
\end{abstract}

\section{Introduction}

The addition of ceramic particles into a metallic matrix is regarded as a possible way, how to improve the mechanical properties of construction materials, e.g. their toughness and fracture resistance, and to reduce their weight at the same time. Lewandowski et al [1] investigated the changes in the work hardening of the 7XXX aluminium alloys as caused by the addition of $\mathrm{SiC}$ particles having the average sizes of either $5 \mu \mathrm{m}$ or $13 \mu \mathrm{m}$. The composites consisting of partially stabilised zirconia and steel were the subject matter in the references [2] and [3]. In [2], Guo et al reported enhanced dynamic mechanical properties of the 2Y-PSZ/steel; the improvement of the mechanical properties was explained by the martensitic transformation of the metallic matrix in the process of the transformation-induced plasticity (TRIP). Wittig et al [3] studied the wear and plastic behaviour of the titanium activated pre-forms based on monoclinic $\mathrm{ZrO}_{2}$ and/or on the partially stabilised $\mathrm{ZrO}_{2}$ powders that were infiltrated by the X38CrMoV5-1 steel. Finally, it was concluded in [3] that the metal matrix composites (MMCs) based on monoclinic $\mathrm{ZrO}_{2}$ show non-catastrophic failure because the plastic deformation occur prior the failure. The martensitic transformation was observed in all MMCs under study. However, this transformation ran in $\mathrm{ZrO}_{2}$ in this particular case [3]. The extent of the tetragonal to monoclinic phase transformation was affected by the type of the $\mathrm{ZrO}_{2}$ powder and by the dwell time of the infiltration process. 
The results published in the literature show clearly that the mechanical properties of such MMCs are affected not only by the mechanical properties of the individual constituents but also by their interaction at the interfaces. In order to illustrate the consequences of the interaction between the TRIP steel and the ceramics and to understand the processes running at their interface, we deposited thin films of the TRIP steel on the ceramic substrates. The first task of our work was to clarify, if the steel can be deposited in a magnetron sputtering process from a steel target without changing the chemical composition of the steel. In the second part of the work, we investigated the effect of the interface interaction on the surface morphology, phase composition and the preferred orientation of crystallites in the thin films. Because a strong influence of the interface roughness on the microstructure of the thin films was expected, ceramic substrates with different surface roughness were used for the deposition. In addition, reference thin films were deposited on singlecrystalline silicon wafers.

\section{Experimental details}

Thin films of the TRIP steel under study were deposited on various substrates in a magnetron sputtering process from a target with the chemical composition given in Table 1. The target was made from TRIP steel, which was produced by casting at the ACTech Company (Freiberg, Germany). The magnetron deposition was done in argon atmosphere at the working pressure of 0.5 $\mathrm{Pa}$. No bias voltage was applied.

Four different substrates were used for the deposition of the steel thin films in order to be able to assess the influence of the substrate surface roughness and morphology on the microstructure of the thin films: polished $\mathrm{Si}$ wafer, $\mathrm{ZrO}_{2}$ ceramics that was partially stabilised by $\mathrm{MgO}$ (Mg-PSZ) and ATZ ceramics. The ATZ ceramics is a dispersion ceramics containing approximately $80 \mathrm{wt} \%$ of the $\mathrm{Y}_{2} \mathrm{O}_{3}$-stabilised $\mathrm{ZrO}_{2}$ and approximately 20 wt $\% \mathrm{Al}_{2} \mathrm{O}_{3}$. The alternative surface roughness of $\mathrm{ATZ}$ was $\mathrm{Ra} \approx 0.2 \mu \mathrm{m}$ and $\mathrm{Ra} \approx 8 \mathrm{~nm}$ for the lapped side and for the polished side, respectively.

Table 1. Chemical composition of the TRIP steel target and of TRIP steel thin films on different substrates, and their thickness.

\begin{tabular}{|c|c|c|c|c|c|c|c|c|c|}
\hline \multirow{2}{*}{\multicolumn{2}{|c|}{ Sample }} & \multirow{2}{*}{$\begin{array}{c}\text { Thickness } \\
\text { of film } \\
{[\mu \mathrm{m}]} \\
(\mathrm{SEM})\end{array}$} & \multirow{2}{*}{ Method } & \multicolumn{6}{|c|}{ Chemical composition of the thin films [wt. \%] } \\
\hline & & & & $\mathrm{Fe}$ & $\mathrm{Cr}$ & $\mathrm{Ni}$ & $\mathrm{Mn}$ & $\mathrm{Si}$ & $\mathrm{Al}$ \\
\hline \multicolumn{2}{|c|}{ Steel target } & & $\begin{array}{c}\text { GDOES } \\
\text { EDX }\end{array}$ & $\begin{array}{l}70.5 \pm 0.1 \\
70.5 \pm 2.1\end{array}$ & $\begin{array}{l}13.5 \pm 0.1 \\
14.8 \pm 2.5\end{array}$ & $\begin{array}{c}8.1 \pm 0.02 \\
6.7 \pm 0.3\end{array}$ & $\begin{array}{c}5.8 \pm 0.03 \\
6.0 \pm 0.3\end{array}$ & $\begin{array}{c}1.4 \pm 0.02 \\
1.6 \pm 0.1\end{array}$ & $\begin{array}{l}0.1 \pm 0.01 \\
0.2 \pm 0.05\end{array}$ \\
\hline \multirow{4}{*}{ Substrate } & $\begin{array}{l}\text { polished } \\
\text { Si wafer } \\
\end{array}$ & $1.3 \pm 0.2$ & $\begin{array}{c}\text { GDOES } \\
\text { EDX }\end{array}$ & $\begin{array}{l}70.7 \pm 0.2 \\
71.8 \pm 2.0\end{array}$ & $\begin{array}{l}14.0 \pm 0.4 \\
14.5 \pm 1.5\end{array}$ & $\begin{array}{l}7.8 \pm 0.1 \\
6.9 \pm 0.2\end{array}$ & $\begin{array}{l}4.6 \pm 0.1 \\
5.7 \pm 0.2\end{array}$ & $\begin{array}{l}0.9 \pm 0.1 \\
0.8 \pm 0.1\end{array}$ & $\begin{array}{l}0.1 \pm 0.01 \\
0.1 \pm 0.01\end{array}$ \\
\hline & $\begin{array}{c}\text { extruded } \\
\mathrm{MgO} \cdot \mathrm{ZrO}_{2}\end{array}$ & $2.9 \pm 0.3$ & \multirow{3}{*}{ EDX } & $71.7 \pm 2.2$ & $15.0 \pm 0.6$ & $6.0 \pm 0.2$ & $6.0 \pm 0.2$ & $1.0 \pm 0.1$ & $0.3 \pm 0.04$ \\
\hline & $\begin{array}{c}\text { polished } \\
\mathrm{Al}_{2} \mathrm{O}_{3} \cdot \mathrm{ZrO}_{2}\end{array}$ & $1.46 \pm 0.04$ & & $71.6 \pm 2.1$ & $14.6 \pm 2.5$ & $7.1 \pm 0.3$ & $5.8 \pm 0.3$ & $0.7 \pm 0.1$ & $0.1 \pm 0.05$ \\
\hline & $\begin{array}{c}\text { lapped } \\
\mathrm{Al}_{2} \mathrm{O}_{3} \cdot \mathrm{ZrO}_{2}\end{array}$ & $1.6 \pm 0.1$ & & $71.4 \pm 2.1$ & $14.8 \pm 2.7$ & $7.2 \pm 0.3$ & $5.6 \pm 0.3$ & $0.8 \pm 0.1$ & $0.1 \pm 0.04$ \\
\hline
\end{tabular}

Subsequently, these thin films were studied regarding their chemical composition and microstructure. The chemical composition of the thin films (and the target used for the deposition) was determined using a combination of the glow-discharge optical emission spectroscopy (GDOES) and the energy dispersive analysis of the characteristic X-rays in a scanning electron microscope (SEM/EDX). SEM with the registration of the secondary electrons was employed for investigation of the morphology and the thickness of the thin steel films. The phase compositions of the samples were concluded from the X-ray diffraction (XRD) and glancing-angle XRD (GAXRD) measurements with $\mathrm{CuK} \alpha$ radiation. The XRD measurements were done on a conventional Bragg-Brentano 
diffractometer. GAXRD experiments were performed on a D8 diffractometer (Bruker AXS) equipped by a Goebel mirror in the primary beam and by a Soller collimator and a flat LiF monochromator in the diffracted beam. The preferred orientation of crystallites in the thin films was analysed via pole figure measurements that were carried out using the CoK $\alpha$ radiation on a D8 Discover diffractometer from Bruker, which was equipped with a Eulerian cradle and a twodimensional position sensitive detector (GADDS from Bruker).

The local phase analysis was performed with the aid of the transmission electron microscopy with high resolution (HRTEM) that was combined with Fast Fourier Transformation (FFT) of the HRTEM micrographs. HRTEM measurements were done on a JEM 2010 FEF from Jeol at the acceleration voltage of $200 \mathrm{kV}$. The high resolution was achieved by using ultra-high resolution objective lens $\left(\mathrm{C}_{\mathrm{s}}=0.5 \mathrm{~mm}\right)$ and an in-column energy filter to remove the inelastic electrons from the HRTEM micrograph. HRTEM samples were mechanically thinned, etched by ion beam and finally plasma cleaned.

\section{Results}

The chemical composition of the PVD thin steel films matches well with the chemical composition of the TRIP steel target (Table 1). GDOES and EDX/SEM provide similar results, as it was verified on the steel target and on the thin film deposited on the polished Si wafer. It was impossible to measure the other samples with GDOES, as the substrates were not electrically conducting.

The XRD phase analysis gave the evidence that the target contains austenite as the dominant phase (Fig. 1a). The dominant phase in the films was ferrite (Figs. 1b-e). The change of the phase composition is due to the deposition process.

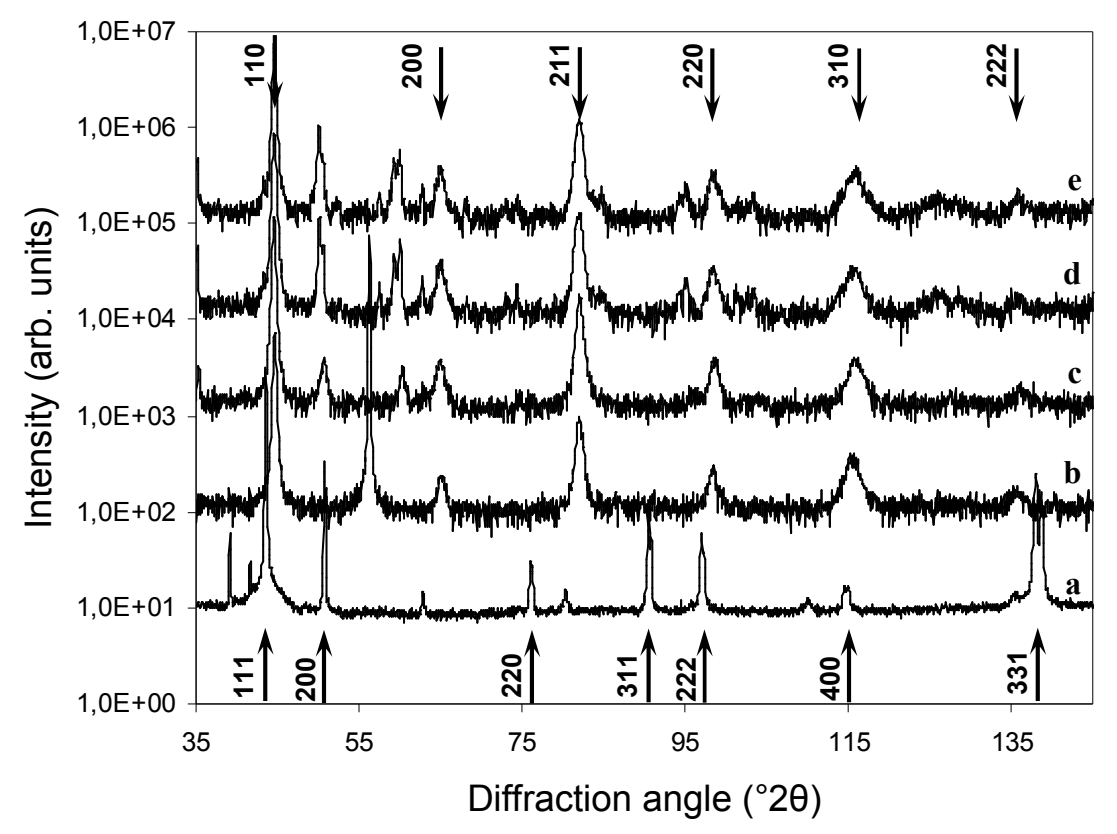

Fig. 1. XRD: Diffraction patterns of the TRIP steel target (a) and of the steel thin film on different substrates: polished $\mathrm{Si}$ wafer (b), extruded $\mathrm{MgO} \cdot \mathrm{ZrO}_{2}$ (c), polished $\mathrm{ZrO}_{2} \bullet \mathrm{Al}_{2} \mathrm{O}_{3}$ (d), and lapped $\mathrm{ZrO}_{2} \bullet \mathrm{Al}_{2} \mathrm{O}_{3}$ (e). Diffraction lines from austenite are labelled by corresponding diffraction indices at the bottom, diffraction lines from ferrite at the top of the figure. The other, not labelled diffraction lines come from the corresponding substrates. 
Although no diffraction lines from austenite were detected in the steel film deposited on the Si wafer, HRTEM/FFT (Figs. 2 and 3) discovered both ferritic and austenitic nanocrystalline domains in this sample. HRTEM image (Fig. 2a) shows several fcc nanocrystallites and moiré pattern due to a small mutual rotation of these nanocrystallites. The crystallographic orientation of the nanocrystalline domains in the electron beam was determined with the aid of the Fast Fourier Transformation of the HRTEM image (Fig. 2b). The direction of the primary electron beam was $[10 \overline{1}]$, the crystallographic directions $(111),(020)$ and $(202)$ in the reciprocal lattice are perpendicular to the direction of the primary beam. To index the diffraction spots in the FFT pattern, both the interplanar spacings and the angles between the diffracting planes were considered. From the presence of the diffraction spots 111 and 020, the presence of the face-centred cubic (fcc) was finally concluded.

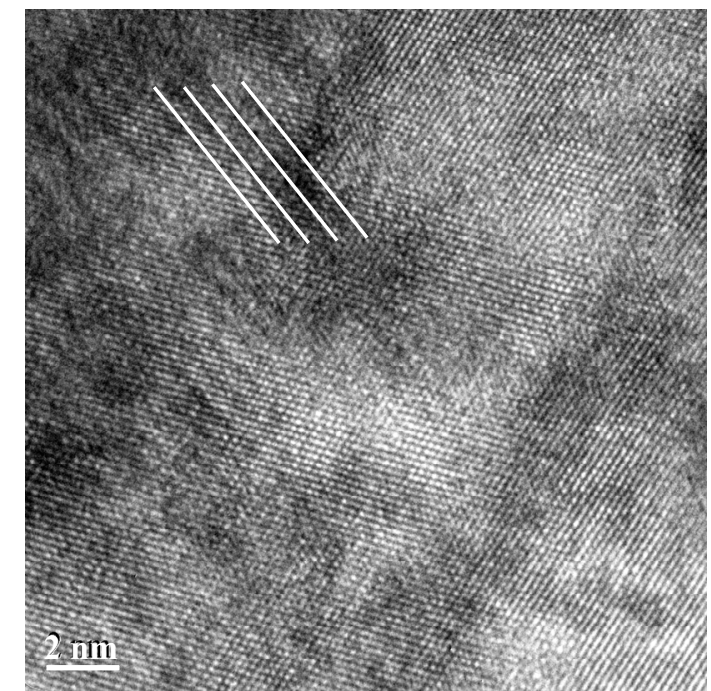

a)

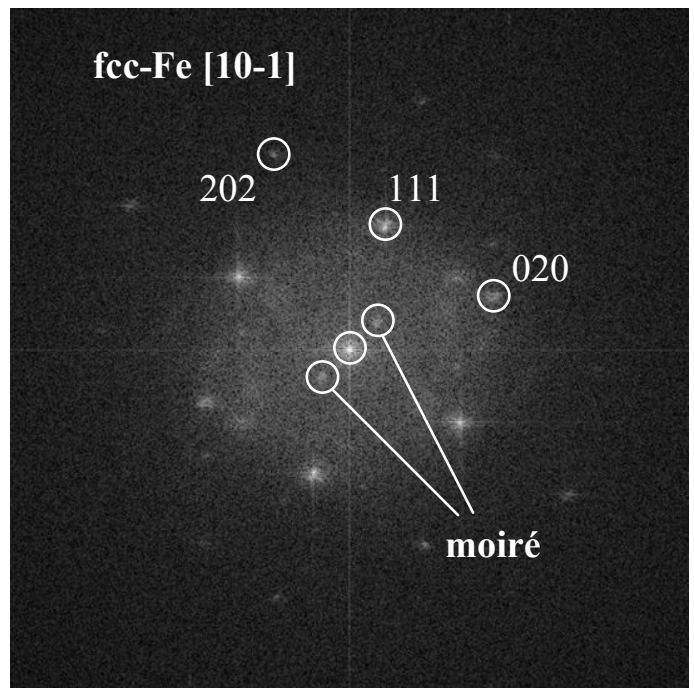

b)

Fig. 2. HRTEM micrograph of the steel thin film on the polished Si wafer shows moiré pattern due to a small mutual rotation of fcc-Fe nanocrystallites (a) and FFT of this area with intensity maxima near centre that are typical for the moiré patterns (b).

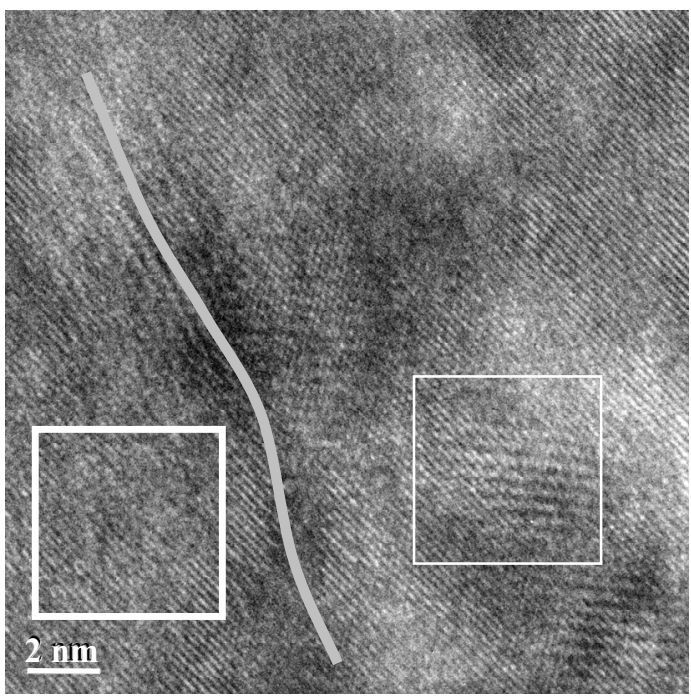

a)

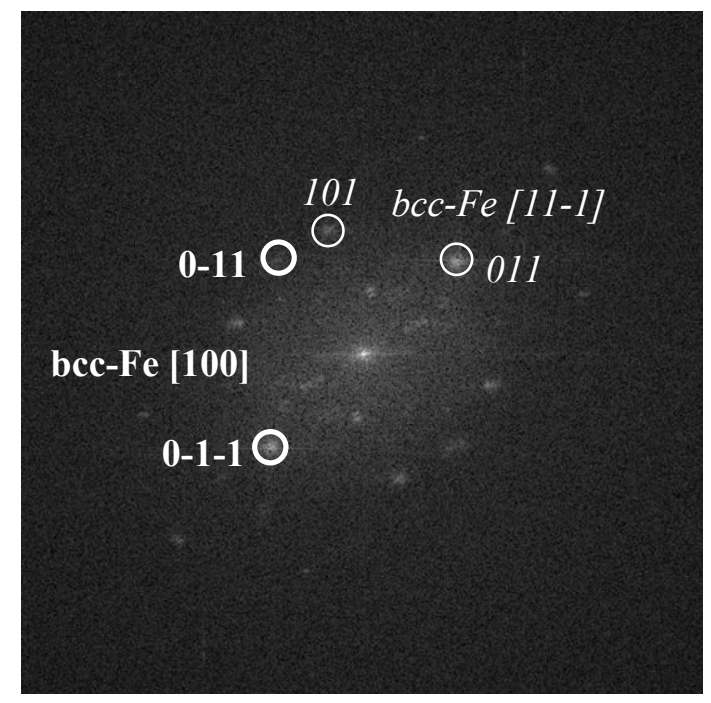

b)

Fig. 3. HRTEM micrograph of the steel thin film on the polished $\mathrm{Si}$ wafer shows two bcc-Fe nanocrystallites, with quadrat labelled, and the boundary, grey labelled (a) and FFT of the whole area with reflexes of this crystallites (b). 


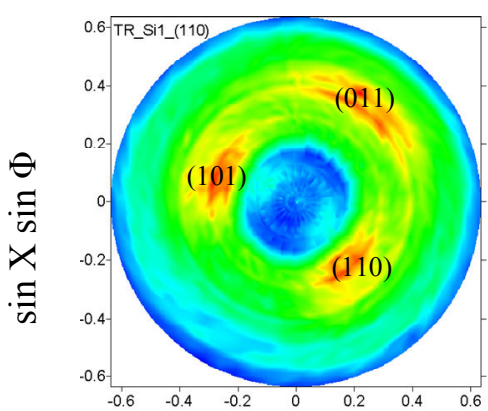

a)

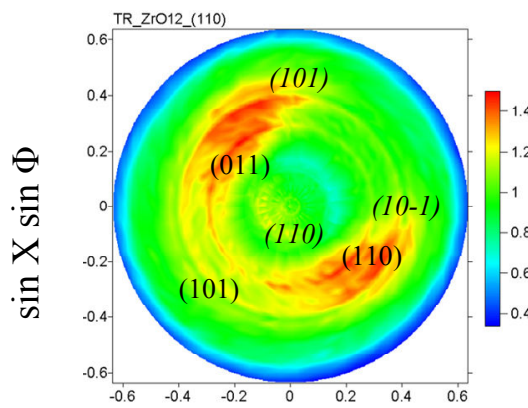

d)

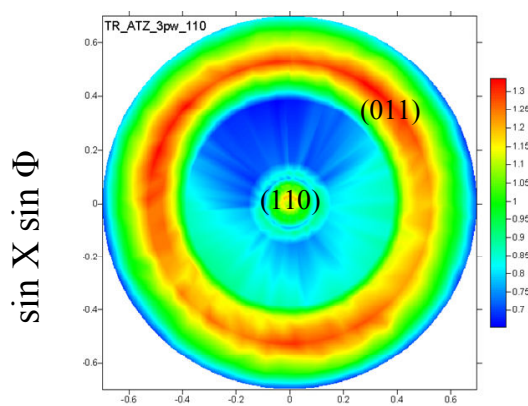

g)

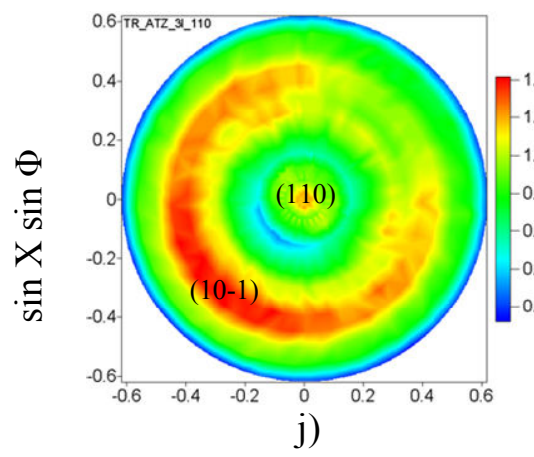

$\sin X \cos \Phi$

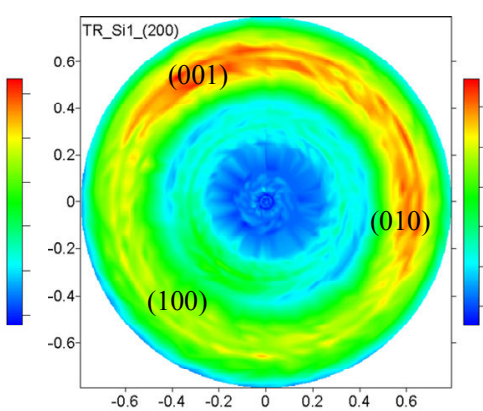

b)

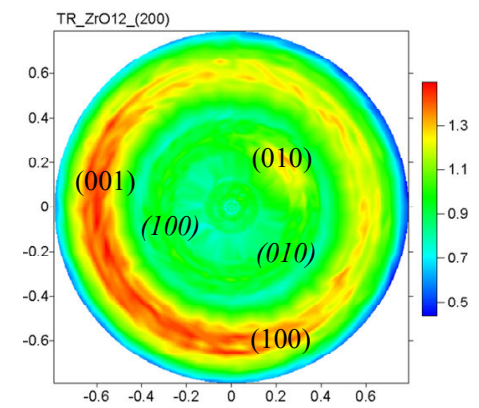

e)

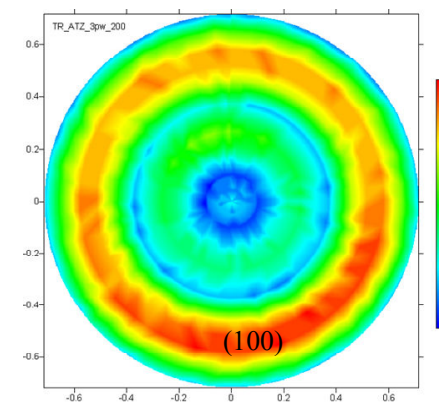

h)

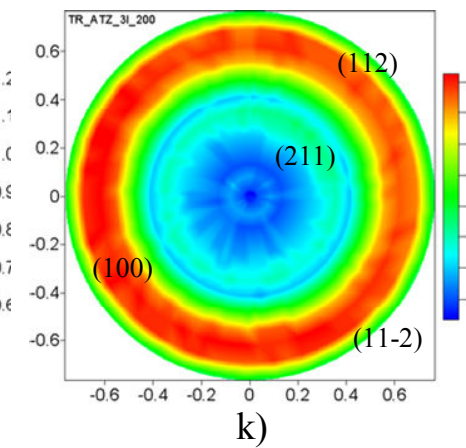

$\sin X \cos \Phi$

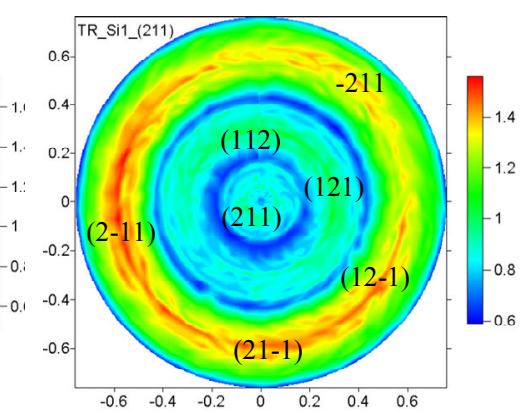

c)

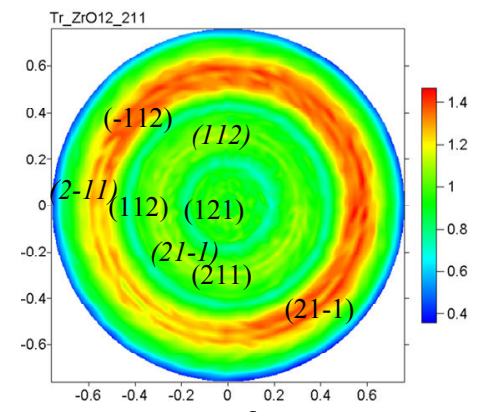

f)

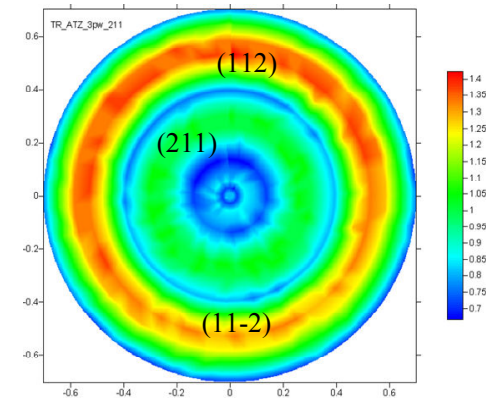

i)

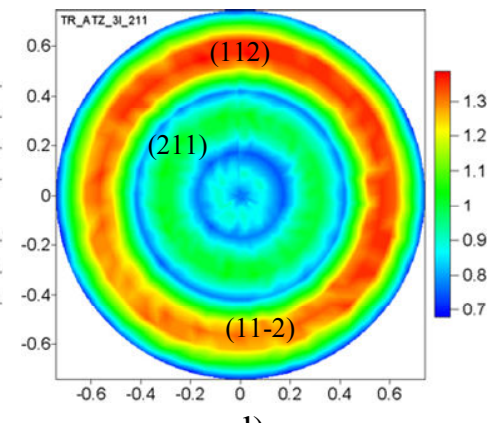

1)

$\sin \mathrm{X} \cos \Phi$

Fig. 4. Pole figures (110), (200) and (211) measured for ferrite in the steel thin films on the Si wafer $(\mathrm{a}, \mathrm{b}, \mathrm{c})$, on the extruded $\mathrm{MgO} \cdot \mathrm{ZrO}_{2}(\mathrm{~d}, \mathrm{e}, \mathrm{f})$, on the $\mathrm{ZrO}_{2} \bullet \mathrm{Al}_{2} \mathrm{O}_{3}$, polished (g, h, i) and lapped (j, $\mathrm{k}$, 1). $\mathrm{X}$ is the inclination of the sample from the coplanar geometry and $\Phi$ the rotation around the normal direction to the sample surface.

The HRTEM image from Fig. 3 shows two nanocrystallites of ferrite (body-centred cubic, bcc) with the orientations [100] and [11 $\overline{1}]$ and the boundary between them. On the left-hand side of Fig. 3b, directions (0-1-1) and (0-11) in the reciprocal lattice are perpendicular to the [100] direction of the primary electron beam. On the right-hand side of Fig. 3b, the crystallographic directions (101) and (011) in the reciprocal lattice are perpendicular to the [11 $\overline{1}]$ direction of the 
primary electron beam. The crystallographic directions belonging to the [100] orientation of the nanocrystalline domain are label in bold font, the crystallographic directions belonging to the [11 $\overline{1}$ ] orientation in italics.

Fig. 4 shows the XRD pole figures of ferrite measured in the TRIP steel thin films deposited on different substrates. In the thin film deposited on the Si wafer (Fig. 4a), the crystallites were preferentially oriented with their direction $\{111\}$ perpendicular to the sample surface. This preferred orientation is most probably driven by the anisotropy of the elastic constant and/or by the anisotropy of the Young modulus, $\mathrm{E}_{111}>\mathrm{E}_{100}$ [4], which favours the development of the $\{111\}$ texture with increasing residual stress [5]. However, the texture direction $\{111\}$ is inclined of about $10^{\circ}$ from the normal direction. Another evident phenomenon is the presence of the in-plane preferred orientation, which can be deduced from the variation of the diffracted intensity with the rotation of the sample around its normal.

Thin films of the TRIP steel deposited on the extruded $\mathrm{MgO} \cdot \mathrm{ZrO}_{2}$ have two texture components, $\{111\}$ and $\{110\}$. The texture component $\{111\}$ is inclined of about $20^{\circ}$ from the surface normal direction (Fig. $4 \mathrm{~b}$, with regular font labelled), the texture component $\{110\}$ of about $14^{\circ}$ (Fig. 4b, with italics font labelled). The modulation of the intensity with the sample rotation around its normal is substantially weaker than for the TRIP steel thin film deposited on the silicon substrate. In thin films deposited both on polished and on lapped $\mathrm{ZrO}_{2} \bullet \mathrm{Al}_{2} \mathrm{O}_{3}$ substrates (Fig. 4c-d), a weak fibre texture $\{110\}$ was observed.

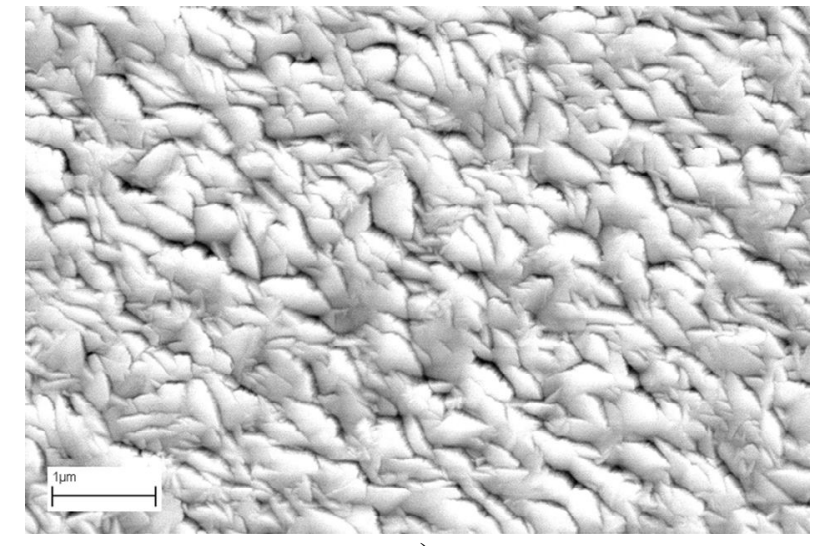

a)

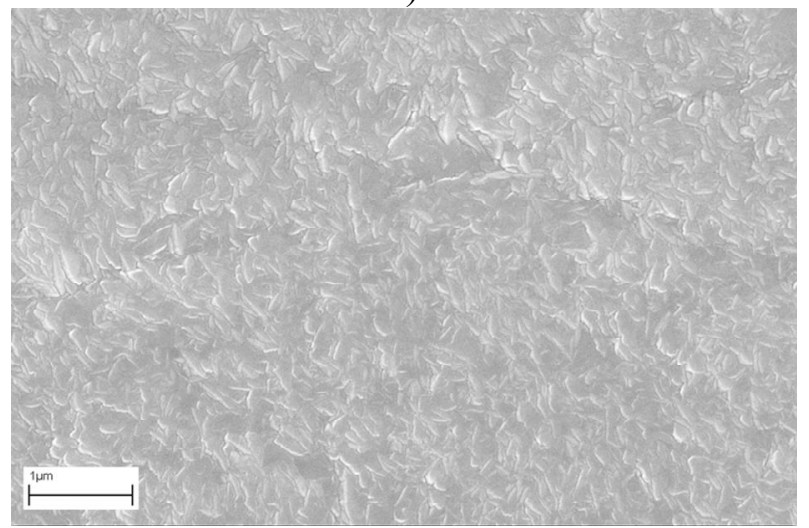

c)

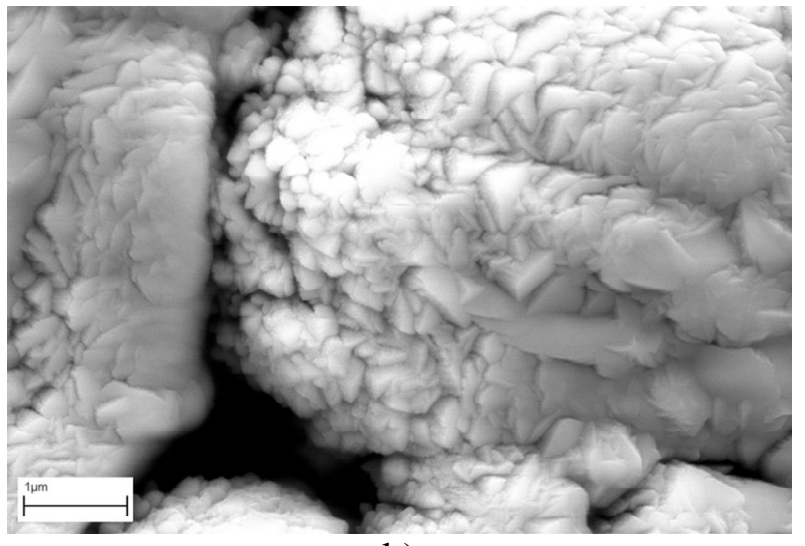

b)

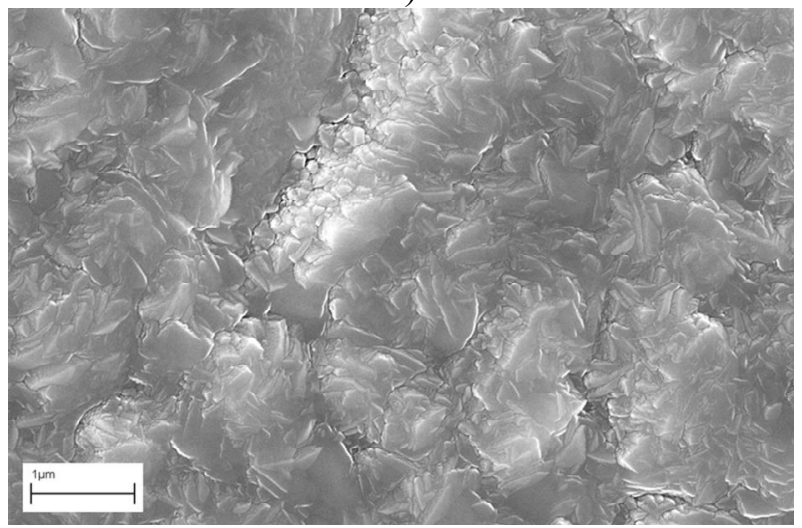

d)

Fig. 5. Morphology of the TRIP steel thin films on different substrates (SEM): the polished $\mathrm{Si}$ wafer (a), extruded $\mathrm{MgO} \cdot \mathrm{ZrO}_{2}$ (b), polished $\mathrm{ZrO}_{2} \bullet \mathrm{Al}_{2} \mathrm{O}_{3}$ (c) and lapped $\mathrm{ZrO}_{2} \bullet \mathrm{Al}_{2} \mathrm{O}_{3}$ (d).

The possible factors influencing the preferred orientation of crystallites in the TRIP steel thin films are the anisotropy of the elastic constants in combination with the residual stress as discussed above, the morphology of the substrates affecting the morphology of the thin films and the interaction between the substrate and the film. The GAXRD data fitting using the MAUD 
software [6] (Rietveld-like routine suitable for analysis of the GAXRD data) yielded biaxial residual stress of $(1.22 \pm 0.002) \mathrm{GPa}$ in the steel thin film deposited on the Si wafer and almost stress-free state of the steel thin film deposited on the extruded $\mathrm{MgO} \cdot \mathrm{ZrO}_{2}$ substrates. For calculation of the residual stress, the Young modulus of $191 \mathrm{GPa}$ and the Poisson ratio of 0.24 were used, which were determined for these TRIP steels via acoustic discharge method [7].

In order to reveal the possible correlation between the texture of the thin films and their morphology, the surface of the thin films was investigated using scanning electron microscopy (Fig. 5). It was found that the thin films replicate the morphology of the surfaces of the substrates. This effect was significant for extruded $\mathrm{MgO} \cdot \mathrm{ZrO}_{2}$, where the pores in the substrate were not covered over during the deposition of the steel films. Furthermore, it follows from the comparison of the preferred orientation of crystallites with the morphology of the thin films that the preferred orientation is influenced rather by the choice of the substrate material (and thus by the possible interaction between the substrate and the film) than by the morphology of the film, which strongly correlates with the roughness of the substrate surface. An exception is the extruded substrate (Fig. $5 b)$ that has an extremely large interface roughness. As mentioned above, the TRIP steel coating deposited on the extruded $\mathrm{MgO} \cdot \mathrm{ZrO}_{2}$ substrate was practically free of the residual stress, because the residual stress can relax easily during the large surface area of the sample.

\section{Summary}

TRIP steel with a complex chemical composition could be deposited successfully using magnetron sputtering. The chemical composition of the deposited steel films agrees well with the composition of the target. However, the phase composition of the thin films was different from the phase composition of the target. The target contained austenite as the major phase, whereas the coatings consisted mainly of ferrite. Only traces of austenite were found in selected coatings by using HRTEM. It was found that the morphology and the texture of the TRIP steel thin films are predominantly controlled by the quality of the substrate surface and by the choice of the substrate material, respectively. This encourages us to believe that the interface between the TRIP steel and the $\mathrm{ZrO}_{2}$-based ceramics is a quite important factor, which influences the mechanical properties of the composites consisting of TRIP steel and $\mathrm{MgO}$ stabilised $\mathrm{ZrO}_{2}$.

\section{Acknowledgement}

This work was financially supported by the German Research Foundation (DFG) in frame of the Collaborative Research Centre 799.

\section{References}

[1] J.J. Lewandowski, D.S. Liu and C. Liu: Scripta Metallurgica et Materialia Vol. 25 (1991), p. 21-26.

[2] Y. Guo, Y. Zhou, X. Duan, D. Li and T. Lei: Ceramics International Vol. 30 (2004), p. 75-80.

[3] D. Wittig, A. Glauche, C.G. Aneziris, T. Minghetti, C. Schelle, T. Graule and J. Kuebler: Mat. Sci. Eng. A Vol. 488 (2008), p. 580-585.

[4] T.H. Courtney: Mechanical Behavior of Materials. McGraw-Hill, New York, (1990).

[5] K. Kremmer, O. Yezerska, G. Schreiber, M. Masimov, V. Klemm, M. Schneider and D. Rafaja: Thin Solid Films Vol. 515 (2007), p. 6698-6706.

[6] Information on http://www.ing.unitn.it/ maud/

[7] G.S.Verma: Nature Vol. 176 (1955), p. 27-28. 